\title{
Emotional Distress Associated with Gynecologic and Breast Cancer in Beni-Suef City
}

\author{
Hanan Elzeblawy Hassan', Magda Mohamed Mohamed Bayoumi², Azza Mohamed Elsayed Atwa ${ }^{3}$ \\ ${ }^{1}$ Lecturer of Maternal \& Newborn Health Nursing, Faculty of Nursing, Beni-Suef University, Egypt \\ Corresponding Author E-mail: nona_nano_1712@yahoo.com \\ ${ }^{2}$ Lecturer of Medical-Surgical Nursing Department, Faculty of Nursing, Beni-Suef University, Egypt \\ ${ }^{3}$ Lecturer of Obstetric \& Gynecology Nursing, Faculty of Nursing, Sohag University, Egypt
}

\begin{abstract}
Background: All women are at risk for breast and gynecologic cancer. There is no doubt that breast and gynecologic cancer is a stressful experience by creating heavy psychological trauma for the woman and has great impact on psychological and emotional health of women. Depression and anxiety consider the emotional disturbances which usually associated with cancer. Aim: assess prevalence rate and investigate the emotional effects of gynecologic and breast cancer. Subjects and Methods: For this study, data were collected through in-depth interviews for the convenience of 200 cancers diagnosed female who were admitted in inpatient wards and/or attending to outpatient gynecological and surgery clinics at University Hospital and General Hospital in Beni-Suef city. Results: The findings of this study indicated that, all types of gynecologic and breast cancer women suffered from different degrees of anxiety and depression. Breast, ovarian, cervical, vulval cancers have significant relations with symptoms of depression scale score. Emotional distress symptoms were severe in women aged 30-40 years, the secondary education level. Depression and anxiety symptoms were more observable in housewives, urbanized, nuclear and not crowded families, compared with working, rural, extended and crowded ones. A statistically significant impact of pain related menstruation, surgical intervention and its type and symptoms of depression scale score. Conclusion: Based on the findings of the present study, it can be concluded that, there is a statistically significant association between cancer women and emotional distress symptoms.
\end{abstract}

Keywords: Breast, Gynecologic, Cancer, Depression, Anxiety.

\section{Introduction}

Cancer is the most significant worldwide health problem with wide geographical variation in incidence and it is also becoming an important item in every country's health agenda. Cancer is the unlimited growth and spread of cells, the growth most often invades surrounding tissue and can metastasize to distant sites. It can affect any part of the body. ${ }^{(1)}$ Cancer begins when cells in a part of the body start to grow out of control. There are many types of cancer, but they all begin because of out-of-control growth of abnormal cells. ${ }^{(2)}$ There are five main types of cancer that affect a woman's reproductive organs: cervical, ovarian, uterine, vaginal, and vulvar. As a group, they are referred to as gynecologic cancer. (A sixth type of gynecologic cancer is the very rare Fallopian tube cancer.) ${ }^{(3)}$

Breast malignant neoplastic disease and hormone receptor positive $(\mathrm{HR}+)$ breast cancer incidence vary across the world with higher incidence in developed nations. Breast cancer is the most common malignancy among women in most developed and developing areas of the globe with almost a million new lawsuits each year. It accounts for about $21 \%$ of all cancers among women worldwide. The incidence rates of breast malignant neoplastic disease are higher in North America, Northern and Western Europe, intermediate in South America and Southern Europe and lowest in Africa and Asia. The distribution of breast cancer within developing countries indicates a higher incidence of breast cancer in urban than in rural areas, a fact that nevertheless needs to be clearly established. So, overall we see a pattern where breast cancer incidence is higher in developed regions of the globe. ${ }^{(4)}$

Breast cancer is the second leading cause of cancer death for women in the United States, after lung cancer. Approximately 40,290 women and 440 men will die from the disease in 2015. ${ }^{(5)}$ Combining all age groups, white (nonHispanic) women are more likely to develop breast cancer than black women. However, black women are more likely to die of breast cancer than white women. ${ }^{(6,7)}$ From 2007 2011, breast cancer incidence rates remained stable in white women and increased by $0.3 \%$ per year in black women. The incidence of in situ breast cancer remained stable for all women during this same time period. On January 1, 2011, in the United States there were approximately 2,899,726 women alive who had a history of breast cancer. ${ }^{(8)}$ In addition to invasive cancers, 60,290 new cases of in situ breast cancer diagnosed among women in the US in 2015, approximately 50,041 of which will be ductal carcinoma in situ. ${ }^{(5)}$

Proper surgical evaluation remains the cornerstone for the management of patients with breast cancer. Mastectomy is recommended for those with large tumors, widespread cancer, more than one tumor in the same breast, recurrent tumors, advanced local disease, previously radiated breasts, tumor located in part of the breast that would give a strange appearance if lumpectomy is performed, Paget's disease (if extensive) and for males with breast cancer. Surgical procedures of the lymph nodes, those who have invasive breast cancer much have surgical intervention to the lymph nodes to discover whether the cancer has spread to them. If 


\section{International Journal of Science and Research (IJSR) \\ ISSN (Online): 2319-7064 \\ Index Copernicus Value (2013): 6.14 | Impact Factor (2014): 5.611}

the spread has occurred, the nodes must be removed. Lumpectomy or Breast Conserving Surgery is performed to remove only the tumor plus some normal tissue around it. This can only be done in the early phases of the cancer. ${ }^{(9)}$

Today, cancer is regarded as a chronic illness that has an impact on physical, psychological and sexual life. Established along the data of GLOBOCAN published by the International Agency for research on Cancer a total of 14.1 million new cancer cases developed in the world and 8.2 million deaths caused by the cancer were kept. It was indicated that 19.3 million new cancer cases will pass in the year 2025. The deaths caused by cancer in Turkey ranked as the second among the causes that give way to death. Gynecologic cancer is observed on the top following breast cancer among women that has resulted in death, and has a vital place among cancer types that are most frequently detected by women in Turkey. ${ }^{(10)}$

Ovarian cancer is the second most common gynecologic malignancy in the US with 23,100 cases estimated in the year 2000. ${ }^{(11)}$ Ovarian cancer causes more deaths than any other cancer of the female reproductive system, but it accounts for just around 3\% of all cancers in adult females. The worldwide incidence of ovarian cancer is 238,700 new cases per year, with a global mortality of 151,900 deaths per year. (12) Tubal ligation may reduce the probability of developing ovarian cancer by up to two-thirds. A hysterectomy also seems to cut the danger of contracting ovarian cancer by nearly one-third. ${ }^{(2)}$

Uterine cancer is the most common as more than 52,500 new cases per year. ${ }^{(13)}$ Each year, approximately 35,000 women in the United States get uterine cancer. ${ }^{(14)}$ Surgery is a fundamental part of the management of endometrial cancer. While the former may be limited to simple hysterectomy and removal of the ovaries, the latter is much more involved and includes pelvic washings, omental biopsy or complete omentectomy, pelvic lymph node dissection, and paraaortic lymph node dissection. ${ }^{(15)}$

Cervical cancer tends to occur in midlife. Most cases are found in women younger than 50. It rarely occurs in women younger than 20. Cervical cancer was formerly one of the most usual reasons of cancer death for American women. Only over the last 30 years, the cervical cancer death rate has gone down by more than $50 \%$. The main reason for this change was the increased use of the Pap test. This screening process can detect changes in the cervix before cancer develops. It can also detect cervical cancer early in its most curable stage. The American Cancer Society's estimates for cervical cancer in the United States for 2015 reported about 12,900 new cases of invasive cervical cancer will be diagnosed, about 4,100 women will die from cervical cancer. $^{(16)}$ An estimated 500,000 new instances of cervical cancer are identified every year worldwide, contributing to annual mortality of 270,000 . It is the third most common cancer in women worldwide. ${ }^{(17)}$

Operation may be urged for small tumors in the cervix, particularly when the patient has no sign of metastasis in the lymph node. Some of the surgical procedure is like hysterectomy, which requires removal of the womb; there are two cases of hysterectomy namely simple hysterectomy that involves removal of the womb and the cervix. Radical hysterectomy involves removal of the uterus and about two centimeters of the upper vagina and soft tissues around the cervix, the procedure may be done laparoscopically therefore taking less recovery time but may cause some effect on the bowel and bladder function. (18) Conization involves the surgical removal of a cone-shaped piece of the cervix and possibly the cervical canal as well. The amount of tissue removed depends on the severity of the cancer. ${ }^{(19)}$ The vagina, however, can be a common site of metastatic gynecological cancer, by either direct extension of cervical or vulvar tumors, or through lymphatic or vascular deposits, as seen in endometrial cancer and gestational trophoblastic disease, respectively. Metastatic or direct extension of nongynecologic tumors to the vagina can also occur from the urinary bladder, urethra, periurethral glands, rectum, and rarely the breast, lung, or other sites. Upwards to 30\% of patients with primary vaginal carcinoma have a history of in situ or invasive cervical cancer treated at least 5 years before. Some vaginal cancers are preceded by vaginal intraepithelial neoplasia (VAIN), although the true malignant potential of VAIN is not recognized. Histologically, approximately $90 \%$ of primary vaginal cancers are squamous cell lesions. ${ }^{(20)}$ The treatment approaches for early-stage vaginal cancer include surgical resection or definitive radiotherapy. The advantages of surgery are the preservation of ovarian and sexual function. (21)

Vulvar cancer (VC) is about $3 \%$ to $5 \%$ of all primary gynecologic malignancies; annual incidence rate is about 2 to 3/10. ${ }^{(22)}$ Each year, about 3,500 women in the United States get vulvar cancer. ${ }^{(14)}$ The vast majority of vulvar lesion occurs in the genital skin surface with early symptoms like vulvar itching, pain, small excrescence. The Early diagnosis rate of Vulvar cancer is increasing now. Vulvar cells similar to a cervical cytology brush are expected to become an important creature in the prevention and early diagnosis of vulvar cancer. ${ }^{(22)}$

Vulva cancer: Surgery such as genital radical resection + inguinal lymph node resection for the vulvar traditional standard technique, this surgical inguinal lymph node dissection routinely cut off the large saphenous vein stripping fascia lata. Surgical methods are split into: Local excision of vulvar lesions; Modified radical vulvectomy/ radical local excision; Radical vulvectomy (extensive genital radical surgery) which is split into: a) genital lesions, b) groin lymph node. According to the pathological type: vulvar squamous cell carcinoma and squamous cell carcinoma (malignant melanoma, Paget's disease, basal cell carcinoma, verrucous carcinoma, bartholin adenocarcinoma and sarcoma). ${ }^{(22)}$

Since the 1980s, many studies in the field of psycho oncology have investigated the relationship between coping style and psychological distress, such as depression, among cancer patients. In particular, in addition to psychiatric outcome, the outcome of these interventions on prognosis has been described. Nevertheless, the bulk of such fields has focused on patients with breast cancer, and few have investigated the relationship between psychological distress and the managing style of patients with gynecologic cancer. 


\section{International Journal of Science and Research (IJSR) \\ ISSN (Online): 2319-7064 \\ Index Copernicus Value (2013): 6.14 | Impact Factor (2014): 5.611}

Patients with gynecologic disease, including cancer, who are undergoing surgery, can be particularly vulnerable to distress associated with damage to self image, altered sexual function, and loss of fertility. Furthermore, about 30\% of cancer patients are accounted to be diagnosed with depression or adjustment disorders. We must thus bring into account psychiatric complications among gynecologic cancer patients. ${ }^{(23)}$

Depression is defined as a state that is characterized by much more than an appropriate feeling of sadness) that is often just a normal emotion that anyone would naturally feel when having to cope with and adjust to life's difficulties( , despair, loneliness, low self-esteem, \& self-reproach. ${ }^{(24)}$ Anxiety is a state of mind which develops depending on environmental stimulants that are perceived by the individuals as being dangerous or threatening and have unpleasing effects. ${ }^{(25)}$ It is well recognized that anxiety may occur at any period of the lifespan. Thither are many aspects of everyday life that provoke anxiety, various offices and conditions can increase the frequency and hardness of the anxiety. (26) Anxiety influences people's mood, expectations and motivation, and are the most prevalent mental disorders. ${ }^{(25)}$

\section{Significance of the Study}

Worldwide, more than 12 million people are newly diagnosed with cancer every year. ${ }^{(27)}$ Of 8.2 million cancer deaths in 2012, 65\% occurred in less developed areas. The most prevalent cancers were lung (13.0\%), breast (11.9\%) and colorectum $(9.7 \%)$. ${ }^{(28)}$

Despite the recent, slight decline in prevalence rates, new female cancer cases remain to be overpowering. The American Cancer Society (ACS) issued a 2009 report stating that annually, American women most frequently develop the following cancers (listed in descending order): breast cancer, 192,370 new cases, lung cancer, 103,350 new cases, colon cancer, 71,380 new cases, uterine cancer, 42,160 new cases, lymphoma 33,860 new cases, skin cancer 31,690 new cases, ovarian cancer 21,550 new cases, and cervical cancer 11,270 new cases. ${ }^{(29)}$

Every 7 minutes a woman in America will read of a gynecologic cancer diagnosis, totaling almost 95,000 new cases each year and about 28,500 deaths. Women diagnosed with a gynecologic cancer should seek care first from a gynecologic oncologist. Surveys have proven that when these specialists perform the first surgical operation, especially for ovarian and uterine cancers, women have better results. ${ }^{(13)}$

Egypt holds a population of 30.55 million women ages 15 years and older who are at peril of getting cervical cancer. Current estimates show that every year 866 women are diagnosed with cervical cancer and 373 die from the disease. Cervical cancer ranks as the $13^{\text {th }}$ most frequent cancer among women in Egypt and the $10^{\text {th }}$ most frequent cancer among adult females between 15 and 44 years of age. Data from Egyptian studies provide widely varying estimates on the prevalence of pre-invasive cervical lesions ranging from $1 \%$ to $8 \%$ with an age range from $20-60$ years. Invasive lesions represented $59.6 \%$ of all female genital tract malignancy, according to Egyptian National Cancer Institute data. ${ }^{(30,31)}$

In Egypt, Breast cancer, it is the most common cancer among women, representing $18.9 \%$ of total cancer cases $(35.1 \%$ in women and 2.2\% in men) among the Egypt National Cancer Institute's (NCI) series of 10,556 patients during the year 2001, with an age-adjusted rate of 49.6 per 100,000 people. $(32,9)$ The incidence rate of ovarian cancer during the period from 2008 to 2011 in Lower Egypt (5.1), Middle Egypt (3.6), and Upper Egypt (7.1) /100,000 populations. The calculated number of ovarian cancer cases in 2015 will be 2,434. ${ }^{(33)}$

Although many studies have contributed greatly to our understanding of breast and gynecologic cancer, there are no published data on emotional distress associated with gynecologic and breast cancer in Beni-Suef City. Therefore, this study attempts to describe the level of emotional distress among studies women.

\section{Operational Definitions of Concepts}

Cancer is a group of diseases in which abnormal cells in the body divide and grow out of control. ${ }^{(3)}$

Gynecologic cancer (GC) refers to any cancer that starts in a woman's reproductive organs (ovary, uterus / endometrium, cervix, vagina and vulva). (13, 34) Additional types of gynecologic cancer exist, and include Fallopian tube cancer and primary peritoneal cancer. ${ }^{(14)}$

Ovarian cancer is cancer that develops in the ovaries. Ovaries are reproductive glands found only in females, placed on each side of the uterus ${ }^{(2,3)}$

When cancer starts in the womb, the pear-shaped organ in a woman's pelvis where the baby grows when a woman is pregnant, it is called uterine cancer. The most usual case of uterine cancer is also called endometrial cancer because it forms in the lining of your uterus, called the endometrium. ${ }^{(3,14)}$

Cervical cancer starts in the cells lining the cervix, the lower part of the uterus (womb); this is sometimes called the uterine cervix. (16,14) Cancer cervix is a malignant uncontrolled growth of epithelial cells in the transformation zone, which is the area between the endocervix and ectocervix. ${ }^{(35)}$

Vaginal cancer can start in the vagina itself (primary vaginal cancer) or spread into the vagina from another part of the body (secondary vaginal cancer). ${ }^{(36)}$

Malignant neoplastic disease of the vulva (also known as vulvar cancer) most frequently involves the inside borders of the labia majora or the labia minora. Cancer occurs on the clitoris or in the Bartholin glands less often. ${ }^{(2)}$

A hysterectomy is removing the uterus without removing the ovaries. ${ }^{(2)}$ 


\section{International Journal of Science and Research (IJSR) \\ ISSN (Online): 2319-7064}

Index Copernicus Value (2013): 6.14 | Impact Factor (2014): 5.611

\section{Aim of the Study}

The aim of the present study was to assess prevalence of gynecologic and breast cancer, to find out and highlight the emotional consequences, particularly anxiety/depression, and to ascertain the relationship between emotional state and other factors, including the sociodemographic, obstetric and gynecological characteristics, among adult women with gynecologic and breast cancer in Beni-Suef city.

\section{Research Question}

What is the prevalence rate of gynecologic and breast cancer among adult women in Beni-Suef city?

Are diagnosis and treatment of gynecologic and breast cancer affecting emotional status among women in BeniSuef city?

Are sociodemographic, obstetric and gynecological characteristics significantly implicated in women's emotional status among adult women with gynecologic and breast cancer in Beni-Suef city?

Hypotheses of the study:

We hypothesized that there are no statistically significant differences in the emotional status among adult women with gynecologic and breast cancer at the level of $(\mathrm{p}<0.05)$ that could be attributed to sociodemographic variables and obstetric and gynecological characteristics.

\section{Subjects and Methods}

\subsection{Materials}

\section{Research Design}

An explorer design was selected for the current study.

\section{Research Setting}

Patients were enrolled in surgery and gynecology outpatient clinics and two inpatient wards in Beni-Suef University and General hospital. Two of these wards belong to the department of obstetrics and gynecology and surgery, respectively, between March 2013 and February 2014.

\section{Subjects}

A sample of convenience of 200 predominantly Upper Egyptian women with a primary diagnosis of breast or gynecological cancer and undergoing either intervention or usual care or follow-up.

\section{Case inclusion criteria}

Each woman meeting the following conditions were included in the study:

- Over 18 years of age and volunteered for the study.

- Diagnosed with breast or gynecological cancer (endometrial, cervical, ovarian, vaginal, vulva and Fallopian tube cancer).

- Undergoing either intervention or usual care or follow-up.

- Had no known psychiatric ailment.

\section{Case exclusion criteria}

- Women were receiving only palliative care.
- Women were cognitively impaired.

- Women were having any psychological treatment.

\section{Tools of the Study}

A Structured interviewing questionnaire was designed by the researchers after reviewing related literature. It encompassed three main sections as follows:

The first part included social, demographic and personal data such as age, educational level, occupational status, and income adequacy, family type and residence.

The second part included obstetrical and gynecological history, such as parity, menstrual disturbance, pain related menstruation, history of surgical treatment \& its types.

Third part included questionnaires about emotional distress, to assess women's data were compiled by using the psychological scales. It consisted of two parts;

- Division I: An Arabic version of the Taylor scale. ${ }^{(37)}$

- Division II: An Arabic version of the Beck depression inventory (BDI). ${ }^{(38)}$

\section{Methods}

- The study tool was reviewed \& tested for content validity by five experts from maternity \& gynecological nursing professor, obstetric \& gynecological medicine professor, Psychiatric and mental health nursing professor and medical surgical nursing professor.

- The study was conducted after getting permission from the directorate of university hospital and general hospital in Beni Suef.

- The aim of the study was explained to the women who participated in the research.

- Oral consent was taken from all women who were agreeing to participate after reassuring them about the confidentiality and privacy of the all information and that information will be used only for the purposeful research.

- The researcher interviewed women at either surgery and gynecology outpatient clinics or inpatient departments in Beni-Suef University and general hospital

- Each woman was questioned individually by the researcher. The mean time needed for each sheet was about 25-35 minutes to fill a questionnaire, also the researcher of study help illiterate women in filling their questionnaire.

- The data were compiled by the researcher during the period of 12 months from the start of March 2013 up to the end of February 2014.

\section{Statistical Data Analysis}

The data were computerized and analyzed using the statistical package for social science (SPSS), version 16.0 Data were presented using:

- Descriptive statistics in the form of number, percentage and standard deviation (Mean (SD).

- Statistical tests included: Chi-square $\left(\chi^{2}\right)$ test for analysis of qualitative variables.

- The graphical presentation included Bie and column chart diagrams.

- Statistical significance was considered at P -value $<0.05$ 


\section{International Journal of Science and Research (IJSR) \\ ISSN (Online): 2319-7064}

Index Copernicus Value (2013): 6.14 | Impact Factor (2014): 5.611

\section{Results}

Table (1) summarizes the distribution of the study sample according to their sociodemographic characteristics. It revealed the age of the majority of the study sample (70\%) were $30-40$ years. $41 \%$ of them Illiterate, read and write or Primary education, only $15 \%$ were working. $38 \%$ of them dwell in rural regions. $46.5 \%$ live in extended families. It was noted from the same table that more than half $(54.5 \%)$ of the study subjects did not have decent family income, while merely $1 \%$ of them had enough family income and can save from it.

Table (2) presents the distribution of the study sample according to their obstetrical \& Gynecological history. 75\% of them had irregular menstrual cycle and $81 \%$ had Pain related menstruation, about half $(47 \%)$ of them were nulliparous. 21.5\% performed surgical interference.

The distribution for the studied sample as regards Prevalence rate of breast and gynecologic cancer is presented in Figure (1). It reads that nearly one quarter (24\%, $22.5 \%$ \& $21.5 \%)$ of the studied sample had breast, ovarian \& cervical cancer, respectively.

Table 1: Distribution of the Studied Sample According to their Sociodemographic Characteristics $(\mathrm{N}=200)$.

\begin{tabular}{|l|c|c|}
\hline Variables & Frequency & Percent \% \\
\hline Age & 50 & 25 \\
\hline$>30$ & 140 & 70 \\
\hline $30-40$ & 10 & 5 \\
\hline$>40$ & & \\
\hline & & \\
\hline Educational level & 82 & 41 \\
\hline Illiterate, (read, write) \& Primary education & 81 & 40.5 \\
\hline Secondary education or equal & 37 & 18.5 \\
\hline University education & & \\
\hline & & \\
\hline Occupational status & 30 & 15.0 \\
\hline Working & 170 & 85.0 \\
\hline Jobless (house wife) & & \\
\hline & & \\
\hline Family residence & 124 & 62 \\
\hline Urban & 76 & 38 \\
\hline Rural & & \\
\hline & & \\
\hline Family type & 107 & 5.53 \\
\hline Nuclear family & 93 & 46.5 \\
\hline Extended family & & \\
\hline & & \\
\hline Crowdedness rate & 116 & 58 \\
\hline$\leq 1$ (not crowded) & 84 & 42 \\
\hline$>1$ (crowded) & & \\
\hline & 109 & 54.5 \\
\hline Family income adequacy & 59 & 29.5 \\
\hline Not enough & 30 & 15 \\
\hline Just enough & 2 & 1 \\
\hline A little more than enough & & \\
\hline Enough and saving from it & & \\
\hline & & \\
\hline & & \\
\hline & & \\
\hline & & \\
\hline & & \\
\hline & & \\
\hline & & \\
\hline
\end{tabular}

Figure 1: Prevalence rate of breast and gynecologic cancer

Table 2: Distribution of the Studied Sample According to their obstetrical \& Gynecological history $(\mathrm{N}=200)$.

\begin{tabular}{|l|c|c|}
\hline Variables & Frequency & Percent \% \\
\hline Marital status & & \\
\hline Married & 148 & 74 \\
\hline Single & 52 & 26 \\
\hline Menstrual disturbance & & \\
\hline No & 50 & 25.0 \\
\hline Yes & 150 & 75.0 \\
\hline & & \\
\hline Pain related menstruation & & \\
\hline Yes & 162 & 81.0 \\
\hline No & 38 & 19.0 \\
\hline & & \\
\hline Parity & & \\
\hline Multiparous & 106 & 53 \\
\hline Nulliparous & 94 & 47 \\
\hline & & \\
\hline Surgical treatment & & \\
\hline Yes & 43 & 21.5 \\
\hline No & 157 & 78.5 \\
\hline Types of surgical operation & & \\
\hline Not applicable & 157 & 78.5 \\
\hline Breast surgery & 23 & 11.5 \\
\hline Hysterectomy (simple \& radical) & 7 & 3.5 \\
\hline Vulva \& vaginal surgery & 5 & 2.5 \\
\hline Exploration & 8 & 4.0 \\
\hline
\end{tabular}

Figure (2): Illustrates the relationship between breast and gynecologic cancer of the studied subjects and their emotional distress. It was noted that all types of breast and gynecologic cancer women suffered from different degrees of anxiety and depression. Breast, ovarian, cervical, uterine, vulval cancers have significant relations with symptoms of depression scale score, $(\mathrm{P}<0.05)$. In addition, breast, ovarian, cervical, vaginal and vulval cancers have significant relations with symptoms of the anxiety scale score $(\mathrm{P}<0.05)$.

The distribution of the studied sample as regards emotional distress symptoms based on sociodemographic characteristics is presented in Table (3). It reveals that depression and anxiety symptoms were severe in women aged $30-40$ years $(74.1 \%$ \& $77.8 \%)$, respectively, Secondary education level (49.3\% \& 83.9\%). Depression and anxiety symptoms were more observable in housewives, urbanized, nuclear and not crowded families, compared with working, rural, extended and crowded ones. Age, occupation and educational level had a significant relation with symptoms of anxiousness and depression scale score. 


\section{International Journal of Science and Research (IJSR) \\ ISSN (Online): 2319-7064 \\ Index Copernicus Value (2013): 6.14 | Impact Factor (2014): 5.611}

Table 4: shows the relationship between obstetrical and gynecological history of the studied subjects and their emotional distress. This table portrays a statistically significant impact of marital status, pain related menstruation, parity, surgical interference and its type and symptoms of depression scale score. In addition, pain related menstruation, surgical intervention and its type have significant relations with symptoms of the anxiety scale score.

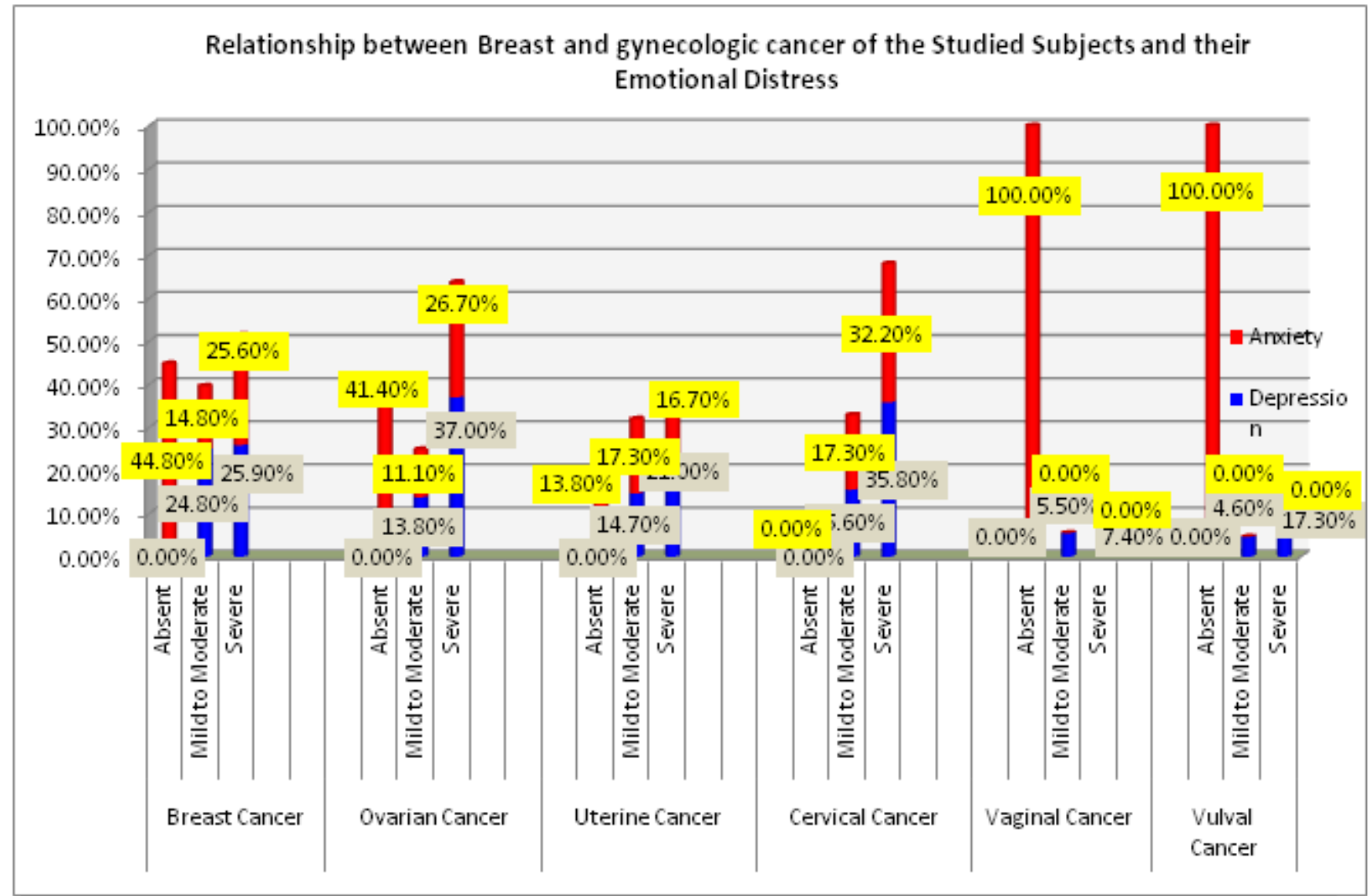

Figure 2: Relationship between Breast and gynecologic cancer of the Studied Subjects and their Emotional Distress.

Table 3: Relationship between Sociodemographic Characteristics of the Studied Subjects and their Emotional Distress

\begin{tabular}{|c|c|c|c|c|c|c|c|c|}
\hline \multirow[b]{2}{*}{ Variables } & \multicolumn{4}{|c|}{ Depression } & \multicolumn{4}{|c|}{ Anxiety } \\
\hline & Absent & $\begin{array}{l}\text { Mild to } \\
\text { moderate }\end{array}$ & Severe & P-Value & Absent & $\begin{array}{c}\text { Mild to } \\
\text { moderate }\end{array}$ & Severe & P-Value \\
\hline \multicolumn{9}{|l|}{ Age } \\
\hline \multirow{2}{*}{$>30$} & 1 & 36 & 13 & \multirow{6}{*}{0.000} & 10 & 28 & 12 & \multirow{6}{*}{0.000} \\
\hline & $10 \%$ & $33.1 \%$ & $16.0 \%$ & & $34.5 \%$ & $34.6 \%$ & $13.3 \%$ & \\
\hline \multirow[t]{2}{*}{$30-40$} & 9 & 71 & 60 & & 18 & 52 & 70 & \\
\hline & $90 \%$ & 65.1 & $74.1 \%$ & & $62.1 \%$ & $64.2 \%$ & $77.8 \%$ & \\
\hline \multirow[t]{2}{*}{ Above 40 years } & 0 & 2 & 8 & & 1 & 1 & 8 & \\
\hline & $0.0 \%$ & $1.8 \%$ & $9.9 \%$ & & $3.4 \%$ & $1.2 \%$ & $8.9 \%$ & \\
\hline \multirow[t]{2}{*}{ Total } & 10 & 109 & 81 & & 29 & 81 & 90 & \\
\hline & $100.0 \%$ & $100.0 \%$ & $100.0 \%$ & & $100 \%$ & $100.0 \%$ & $100.0 \%$ & \\
\hline \multicolumn{9}{|l|}{ Educational level } \\
\hline \multirow[t]{2}{*}{$\begin{array}{l}\text { Illiterate, read \& write \& Primary } \\
\text { education }\end{array}$} & 6 & 46 & 30 & \multirow{6}{*}{0.004} & 7 & 34 & 41 & \multirow{6}{*}{0.000} \\
\hline & $60 \%$ & $42.2 \%$ & $37.0 \%$ & & $24.2 \%$ & $42.0 \%$ & $54.5 \%$ & \\
\hline \multirow{2}{*}{ Secondary education or equal } & 4 & 37 & 40 & & 11 & 35 & 35 & \\
\hline & $40 \%$ & $33.9 \%$ & $49.3 \%$ & & $37.9 \%$ & $43.2 \%$ & $83.9 \%$ & \\
\hline \multirow[t]{2}{*}{ University education } & 0 & 26 & 11 & & 11 & 12 & 14 & \\
\hline & $0.0 \%$ & $23.9 \%$ & $13.7 \%$ & & $37.9 \%$ & $14.8 \%$ & $15.6 \%$ & \\
\hline \multicolumn{9}{|l|}{ Occupational status } \\
\hline \multirow[t]{2}{*}{ Working } & 0 & 12 & 18 & \multirow{4}{*}{0.001} & 2 & 17 & 11 & \multirow{4}{*}{0.016} \\
\hline & $0.0 \%$ & $11.0 \%$ & $22.2 \%$ & & $6.9 \%$ & $21.0 \%$ & $12.2 \%$ & \\
\hline \multirow[t]{2}{*}{ Jobless (house wife) } & 10 & 97 & 63 & & 27 & 64 & 79 & \\
\hline & $100.0 \%$ & $89.0 \%$ & $77.8 \%$ & & $93.1 \%$ & $79.0 \%$ & $87.8 \%$ & \\
\hline \multicolumn{9}{|l|}{ Family residence } \\
\hline \multirow[t]{2}{*}{ Urban } & 5 & 68 & 51 & \multirow{2}{*}{0.693} & 18 & 50 & 56 & \multirow{2}{*}{0.990} \\
\hline & $50.0 \%$ & $62.4 \%$ & $63.0 \%$ & & $62.1 \%$ & $61.7 \%$ & $62.2 \%$ & \\
\hline
\end{tabular}




\section{International Journal of Science and Research (IJSR)}

ISSN (Online): 2319-7064

Index Copernicus Value (2013): 6.14 | Impact Factor (2014): 5.611

\begin{tabular}{|c|c|c|c|c|c|c|c|c|}
\hline Rural & 5 & 41 & 30 & & 11 & 31 & 34 & \\
\hline & $50.0 \%$ & $37.6 \%$ & $37.0 \%$ & & $37.9 \%$ & $38.3 \%$ & $37.8 \%$ & \\
\hline \multicolumn{9}{|l|}{ Family type } \\
\hline \multirow{2}{*}{ Nuclear } & 6 & 50 & 51 & \multirow{4}{*}{0.006} & 15 & 42 & 50 & \multirow{4}{*}{0.600} \\
\hline & $60.0 \%$ & $45.9 \%$ & $63.0 \%$ & & $51.7 \%$ & $51.9 \%$ & $55.6 \%$ & \\
\hline \multirow[t]{2}{*}{ Extended } & 4 & 59 & 30 & & 14 & 39 & 40 & \\
\hline & $40.0 \%$ & $54.1 \%$ & $37.0 \%$ & & $48.3 \%$ & $48.1 \%$ & $44.4 \%$ & \\
\hline \multicolumn{9}{|l|}{ Crowdedness rate } \\
\hline \multirow{2}{*}{ No crowdedness } & 7 & 62 & 47 & \multirow{4}{*}{0.349} & 12 & 43 & 61 & \multirow{4}{*}{0.000} \\
\hline & $70.0 \%$ & $56.9 \%$ & $58.0 \%$ & & $41.4 \%$ & $53.1 \%$ & $67.8 \%$ & \\
\hline \multirow[t]{2}{*}{ Crowded home } & 3 & 47 & 34 & & 17 & 38 & 29 & \\
\hline & $30.0 \%$ & $43.1 \%$ & $42.0 \%$ & & $58.6 \%$ & $46.9 \%$ & $32.2 \%$ & \\
\hline \multicolumn{9}{|l|}{ Family income adequacy } \\
\hline \multirow[t]{2}{*}{ Not enough } & 7 & 62 & 40 & \multirow{8}{*}{0.096} & 15 & 42 & 52 & \multirow{8}{*}{0.001} \\
\hline & $70.0 \%$ & $56.8 \%$ & $49.4 \%$ & & $51.7 \%$ & $51.9 \%$ & $57.8 \%$ & \\
\hline \multirow[t]{2}{*}{ Just enough } & 2 & 32 & 25 & & 14 & 24 & 21 & \\
\hline & $20.0 \%$ & $29.4 \%$ & $30.9 \%$ & & $48.3 \%$ & $29.6 \%$ & $23.3 \%$ & \\
\hline \multirow{2}{*}{ A little more than enough } & 0 & 15 & 15 & & 0 & 15 & 15 & \\
\hline & $0.0 \%$ & $13.8 \%$ & $18.5 \%$ & & $0.0 \%$ & $18.5 \%$ & $16.7 \%$ & \\
\hline \multirow{2}{*}{ Enough and saving possible } & 1 & 0 & 1 & & 0 & 0 & 2 & \\
\hline & $10.0 \%$ & $0.0 \%$ & $1.2 \%$ & & $0.0 \%$ & $0.0 \%$ & $2.2 \%$ & \\
\hline
\end{tabular}

Table 4: Relationship between Obstetrical \& Gynecological history of the Studied Subjects and their Emotional Distress

\begin{tabular}{|c|c|c|c|c|c|c|c|c|}
\hline \multirow[b]{2}{*}{ Variables } & \multicolumn{4}{|c|}{ Depression } & \multicolumn{4}{|c|}{ Anxiety } \\
\hline & Absent & $\begin{array}{l}\text { Mild to } \\
\text { moderate }\end{array}$ & Severe & P-Value & Absent & $\begin{array}{l}\text { Mild to } \\
\text { moderate }\end{array}$ & Severe & P-Value \\
\hline \multicolumn{9}{|l|}{ Marital status } \\
\hline Married & 5 & 86 & 57 & \multirow{4}{*}{0.004} & 23 & 63 & 62 & \multirow{4}{*}{0.170} \\
\hline & $50.0 \%$ & $78.9 \%$ & $70.4 \%$ & & $79.3 \%$ & $77.8 \%$ & $68.9 \%$ & \\
\hline Single & 5 & 23 & 24 & & 6 & 18 & 28 & \\
\hline & $50.0 \%$ & $21.1 \%$ & $29.6 \%$ & & $20.7 \%$ & $22.2 \%$ & $31.1 \%$ & \\
\hline \multicolumn{9}{|l|}{ Menstrual disturbance } \\
\hline No & 2 & 25 & 23 & \multirow{4}{*}{0.331} & 0 & 27 & 23 & \multirow{4}{*}{0.000} \\
\hline & $20.0 \%$ & $22.9 \%$ & $28.4 \%$ & & $0.0 \%$ & $33.3 \%$ & $25.6 \%$ & \\
\hline Yes & 8 & 84 & 58 & & 29 & 54 & 67 & \\
\hline$=$ & $80.0 \%$ & $77.1 \%$ & $71.6 \%$ & & $100.0 \%$ & $66.7 \%$ & $74.4 \%$ & \\
\hline \multicolumn{9}{|l|}{ Pain related menstruation } \\
\hline Yes & 8 & 92 & 62 & \multirow{4}{*}{0.051} & 29 & 60 & 73 & \multirow{4}{*}{0.000} \\
\hline & $80.0 \%$ & $84.4 \%$ & $76.5 \%$ & & $100.0 \%$ & $74.1 \%$ & 81.1 & \\
\hline No & 2 & 17 & 19 & & 0 & 21 & 17 & \\
\hline & $20.0 \%$ & $15.6 \%$ & $23.5 \%$ & & $0.0 \%$ & $25.9 \%$ & $18.9 \%$ & \\
\hline \multicolumn{9}{|l|}{ Parity } \\
\hline \multirow[t]{2}{*}{ Multiparous } & 9 & 52 & 45 & \multirow{4}{*}{0.000} & 17 & 42 & 47 & \multirow{4}{*}{0.965} \\
\hline & $90 \%$ & $47.7 \%$ & $55.6 \%$ & & $58.6 \%$ & $51.9 \%$ & $52.2 \%$ & \\
\hline \multirow[t]{2}{*}{ Nulliparous } & 1 & 57 & 36 & & 12 & 39 & 43 & \\
\hline & $10 \%$ & 52.3 & $44.4 \%$ & & $41.4 \%$ & $48.1 \%$ & $47.8 \%$ & \\
\hline \multicolumn{9}{|l|}{ Surgical Treatment } \\
\hline \multirow[t]{2}{*}{ Yes } & 0 & 12 & 31 & \multirow{4}{*}{0.000} & 0 & 13 & 30 & \multirow{4}{*}{0.000} \\
\hline & $0.0 \%$ & $11.0 \%$ & $38.3 \%$ & & $0.0 \%$ & $16.0 \%$ & $33.3 \%$ & \\
\hline \multirow[t]{2}{*}{ No } & 10 & 97 & 50 & & 29 & 68 & 60 & \\
\hline & $100.0 \%$ & $89.0 \%$ & $61.7 \%$ & & $100.0 \%$ & $84.0 \%$ & $66.7 \%$ & \\
\hline \multirow{2}{*}{$\begin{array}{l}\text { Types of Surgical Operation } \\
\text { Not applicable }\end{array}$} & & & & & & & & \\
\hline & 10 & 97 & 50 & & 29 & 68 & 60 & \\
\hline Not applicable & $100.0 \%$ & $89.0 \%$ & $61.7 \%$ & & $100.0 \%$ & $84.0 \%$ & $66.7 \%$ & \\
\hline \multirow[t]{2}{*}{ Breast surgery } & 0 & 6 & 17 & & 0 & 6 & 17 & \\
\hline & $0.0 \%$ & $5.4 \%$ & $21.0 \%$ & & $0.0 \%$ & $7.3 \%$ & $18.9 \%$ & \\
\hline \multirow{2}{*}{ Hysterectomy (simple \& radical) } & 0 & 3 & 4 & & 0 & 2 & 5 & \\
\hline & $0.0 \%$ & $2.8 \%$ & $4.9 \%$ & 0.000 & $0.0 \%$ & $2.5 \%$ & $5.5 \%$ & 0.000 \\
\hline Vulva \& vaginal surgery & 0 & 3 & 2 & & 0 & 5 & 0 & \\
\hline & $0.0 \%$ & $2.8 \%$ & $2.5 \%$ & & $0.0 \%$ & $6.2 \%$ & $0.0 \%$ & \\
\hline Exploration & 0 & 0 & 8 & & 0 & 0 & 8 & \\
\hline & $0.0 \%$ & $0.0 \%$ & $9.9 \%$ & & $0.0 \%$ & $0.0 \%$ & $8.9 \%$ & \\
\hline
\end{tabular}




\section{International Journal of Science and Research (IJSR) \\ ISSN (Online): 2319-7064 \\ Index Copernicus Value (2013): 6.14 | Impact Factor (2014): 5.611}

\section{Discussion}

According to a recent report, developing countries accounted for 820265 cases (77.7\%) of global estimates for new cases of the commonest gynecologic cancers including cervical, corpus and ovarian cancer in 2009. This made up 12.1\% of the 6.8 million cases of malignant neoplastic disease in developing countries. ${ }^{(39)}$

Malignancies specific to female organs, such as those of the breast, womb, and ovary, tend to have a hormone-related etiology. Reproductive risk factors that increase the vulnerability of women to higher levels of endogenous estrogens seemingly lead to an increased danger of such cancers. The malignancies of these three organs also have higher incidence rates in more affluent or developed countries compared with the developing world. However, among these three organ sites, breast cancer is the most common cancer with the highest incidence in most populations across the world. This difference in incidence between various organ sites may be the result of differences in tissue structure of the organs and their anatomical site, and/or physiological function, which translates into differences in exposure. Cervical cancer is also a malignancy that is specific to women, but possesses a risk profile and epidemiology quite unlike that of cancers of the breast, ovary, or womb. ${ }^{(40)}$

While all women are at risk for gynecologic cancer, this risk generally increases with age. Each year in the United States, about 71,500 adult females are diagnosed with gynecologic cancer and about 26,500 women die from it. (3) The commonest sites of malignant neoplastic disease in females are breast (38.8\%), and ovary (4.5\%). Surveys are published using these Gharbiah data up to 2007 and are limited to specific websites of cancer mainly breasted. ${ }^{41,42)}$, and gynecological cancers. ${ }^{(40)}$ None of these geographicallylimited studies and published rates could be studied as representative of Egypt,

There is no doubt that cancer like other physiological phenomenon has social and emotional aspects and it is classified in the realm of behavioral sciences. This study is executed to assess prevalence rate of breast and gynecologic cancer; and the conceptualization and measurement of important emotional aspects of them. The current study findings showed that nearly one quarter (24\%, 22.5\%, $21.5 \%$ ) of the studied sample was diagnosed breast \& ovarian, and cervical cancer respectively. These results are supported by EL Saghir N. (2008) who reported that, breast cancer is the most common female malignancy in adult females in almost all Arab nations. ${ }^{(43)}$ Each year, about 20,000 women in the United States get ovarian cancer. ${ }^{(3)}$ In 2014, approximately 18,660 new cases were diagnosed in Egypt, and 2,395 new cases of ovarian cancer. The breast and ovarian cancer mortality rate were $21.6 \%$ and $5.0 \%$, respectively. ${ }^{(44)}$ Ovarian cancer causes more destruction than any other gynecologic tumor, other than it accounts for approximately $3 \%$ of all cancers in adult females. ${ }^{(45)}$ U.S. Department of Health and Human Services Statistics showed that, among women in the United States, ovarian cancer is the eighth most common cancer and the fifth leading cause of cancer death. Each year, approximately 22,000 women in the United States get ovarian cancer and about 14,000 died from the disease. (18) Moreover, WHO/ICO (2010) stated that, the incidence of cervical cancer in Egypt by cancer registry at AlGharbia is 2.1 per 100,000 women per year. This condition affects not only the health and lives of the women, but also their children, families and their communities at large. ${ }^{(46)}$ In addition, CDC (2013) reported that, breast cancer is considered the leading cause of cancer death among females in economically developing countries. Prevalence of breast carcinoma is high in Egypt and the cases of breast cancer constitute $29 \%$ of cancer cases treated at the national cancer institute and the most frequent malignant tumor in women worldwide. ${ }^{(32)}$ As well as. In 1998 the Gharbiah Population based Cancer Registry (GPCR) was established in Tanta, the capital of Gharbiah Province as a part of the Middle East Cancer Consortium (MECC), this registry records about 600 cases of breast cancer every year from the 8 districts in the Gharbiah Province. ${ }^{(4)}$

Cancer diagnosis affects the psychological wellbeing of both patients and their collaborators, and effective coping has been proposed to be a conjoint process of common reinforcement. ${ }^{(47)}$ Living with cancer and dealing can exact an emotional toll. You may feel fearful, stressed, or anxious about your appearance and your wellness. Some people may suffer from depression. If feelings of depression persist, professional counseling may be necessary. ${ }^{(48)}$

Female breast cancer survivors report reduced optimism, increased feelings of vulnerability, and causing at least one persistent physical symptom including anemia, tiredness, pain, or sleep disorders. ${ }^{(49)}$ In the present study it was discovered that all the breast cancer patients have high degrees of depression and anxiety (25.9\% \& 25.6\%), respectively, at the diagnosis of breast malignant neoplastic disease. This is expected as the malignant neoplastic disease and its treatment may provoke severe physical and psychological ailments. This result was in line with Shaheen G. (2011) who stated that, breast cancer survivors most frequently report experiencing emotional distress (depression and anxiety symptoms). Breast cancer appears to be more stressful because this disease and its medical treatment can afflict the sense of femininity, perceived sexuality, and fertility of its dupes. Many patients with breast cancer reported heightened levels of anxiety and illness related worries and reduction of energy and ability to perform physical activities. Many of them stated that the diagnosis of the breast cancer was a death sentence for them. ${ }^{(50)}$

The present study illustrated that, more than one third (37.0\%, 35.8\%) of the study sample diagnosed ovarian \& cervical cancer, respectively, and reported severe depression symptoms. Furthermore, more than one quarter (25.6\%, $26.7 \%$ ) of the study sample diagnosed breast \& ovarian cancer, respectively, and reported severe anxiety symptoms. This result had a serious indicator of those women's psychological health problems; this indicated that she needs to review psychological team besides surgical, obstetric and gynecological ones to get effective counseling for their case. This result is congruent with the results of Bloom (2008), who stated that; due to the nature of the disease and treatment modalities typically utilized, many cancer 


\section{International Journal of Science and Research (IJSR) \\ ISSN (Online): 2319-7064 \\ Index Copernicus Value (2013): 6.14 | Impact Factor (2014): 5.611}

survivors report psychosocial effects. ${ }^{(51)}$ Another researcher reported that, it is well recognized that many cancer patients suffer appreciable rates of psychiatric morbidity. The prevalence of distress is approximately $48 \%$ in surveys that used a criterion measure. Significantly, nearly two-thirds of cancer patients report at least one inmate psychosocial need. ${ }^{(52)}$ Similarly, Shaheen, G. et al (2011) discovered that the Psychiatric disorders occur more frequently in patients with advanced cancer than in the general population and 20$30 \%$ of patients with advanced cancer will receive a formal psychiatric diagnosis, the most common being depression. In early cancer, it has been found that genes linked to patients rather than the disease gain the risk of depression. Physical symptoms are more likely to correlate with depressive symptoms when they remain uncontrolled, have high severity and numerous, hence adding to patient burden. ${ }^{(50)}$

The present study results indicated that most of the studied sample's anxiety and depression symptoms were in the mid thirty to forty years. More than one-third (40.5\%) of the study samples had secondary or technical education degree. Age and educational level had a significant relation with emotional distress among women undergoing cancer treatment. This result was close to those of other studies, as that of the American Cancer Society (2013) and Ismail, So, and $\mathrm{Li}$ (2010) who reported that about $25 \%$ of breast and gynecologic cancers are diagnosed in women under the age of 50. ${ }^{(53,54)}$ High degrees of uncertainty are associated with high levels of anxiety, which may cause a negative impact on quality of liveliness as well ${ }^{(54)}$. Thus, interventions alleviate uncertainty and offer social support is required to better quality of life among such patients. When examining the relationship between women's educational level and depression and anxiety, the results show moderately and highly significant correlation (0.004 \& 0.000), respectively. It appears that highly educated ones have other targets to focus on. These findings are congruent with the result of Ell K. et al (2008) as he denotes that, Low education has been associated with the forgetting of medical information and more negative attitudes towards cancer. ${ }^{(55)}$

Touching on the occupational status, the outcomes of the current study revealed that only $15 \%$ of the studied subjects were going. The unemployed had the highest prevalence of economic crisis and anxiety when compared with the employed ones. Housewives have no targets to focus on and destruct their attention from disease. A statistically significant deviation was noted among participants working group in relation to depression $(p=0.001)$ and anxiety $(p=0$. $016)$. However, this result was in line with the study done by Upkong D. (2006) and Ramezanzadeh et.al, (2004) found in their study. They establish that depression and anxiety were observed more in housewives than in outside employees. ${ }^{(56,}$

57) It was contradicted what other researchers found which found that the rate of psychological disorder was higher among working women. ${ }^{(25,58)}$

Financial strain or headache is potential to be prevalent among low-income and minority survivors, thus far the shock of economic strain on low-income survivors' disparities in cancer quality of life (QOL) outcomes remains largely undiscovered. The findings of the present survey showed that more than one half (54.5\%) of the study sample didn't have adequate family income, while merely $1 \%$ of them had enough family income and can save from it. A high statistic significant relationship between women's anxiety symptoms and their family income adequacy. It was not surprising to find that, Psychological distress was more prevalent among poor women than rich ones. This may due to that, the patients belonging to poor families were concerned about themselves and about the treatment expenses because they were unable to bear high expenses of treatment of the breast cancer. These resolutions were confirmed by the fourth world conference (1995) which denoted that statistics or so women and poverty were all too familiar, where women were the majority of 1.3 billion people surviving in extreme poverty. (25) This was in accordance with Ell K., et al., (2008) who reported that, Hispanics with cancer are reported to go through significant cost barriers and out-of-pocket costs and low-income women needing cancer screening follow-up report rates of cost worry up to $41 \%$. Economic stress is also associated with depression, with higher prevalence among low-income populations, with evidence that financial strain and employment are causally related to depression. For many works, women economic stresses are significantly linked with clinical depression and anxiousness. ${ }^{(55)}$

Progressive industrialization and urbanization of Egypt has resulted in almost half of the Egyptian population now living in cities, given the high vulnerability of urban populations to various xenoestrogens and emotional suffering. Based on residence, the results of the present study illustrated that, cancer incidence and its emotional sequel (depression and anxiety) is higher in urban and nuclear families than in rural and extended families in Beni Suef. This difference in development and industrialization translates into differences in exposure to certain synthetic chemicals called xenoestrogens that have been shown to behave like natural hormones within the body and have been implicated in numerous in vitro, animal subjects and human subjects to increase the danger of malignant neoplastic disease. ${ }^{(4)}$ It can conclude that lower emotional distress in women live in extended families can be related to their social support from all members of family. patients had high social support especially their families, which related to patients are contact with their caregivers, friends and relatives which have higher levels of social support than individuals who live in nuclear or have minimal contact with others. These findings are in agreement with the result of Dey S. et al., (2010) who stated that, within developing countries; urban areas tend to be wealthier and developed cancer compared to the rural arenas. Urban incidence of breast malignant neoplastic disease was three to four times higher than rural incidence. They investigated the urban-rural incidence differences of gynecologic malignancies (uterine, ovarian and cervical cancers) to explore if they exhibit the same style that they found for breast cancer. ${ }^{(40)}$

The primary risk factor for emotional suffering, among women of reproductive years and suffering from cancer is nulliparity. It was noticed, from the findings of the present study, that around half (47.0\%) of the studied subjects were nulliparous and about three quarters (74.0\%) were married. Granting to the present study findings, it was found that $68.9 \%$ \& $70.4 \%$ of adult females who were married had 


\section{International Journal of Science and Research (IJSR) \\ ISSN (Online): 2319-7064 \\ Index Copernicus Value (2013): 6.14 | Impact Factor (2014): 5.611}

severe level of anxiety \& depression, respectively, compared to $31.1 \%$ \& $29.6 \%$ for individual singles. In addition, $55.6 \%$ \& $52.2 \%$ of multiparous women had severed level of depression \& anxiety, respectively, compared to $44.4 \%$ \& $47.8 \%$, respectively, for nulliparous ones. This may due to that, Many of women stated that the diagnosis of the cancer was a death sentence for them. The patients were concerned around the fate of the disease. They were very depressed in thinking that what will take place with their children later on their death. This result is congruent with the results of Day S. (2009) who reported that, Egyptian women have reproductive factors which include high parity and long durations of lactation, which when matched with youngonset breast cancer and probable high exposure of the population to environmental sources of estrogens makes Egypt an interesting position to examine breast cancer etiology. ${ }^{(4)}$ A statistically significant impact of marital status and parity among women on their depression level, ( $\mathrm{p}=$ $0.004 \& 0.000$ respectively) was observed.

Based on menstrual disturbance and pain related menstruation among study subject, it is evident that three quarters $(75.5 \%)$ and more than three quarters $(81.0 \%)$ of them suffered an irregular menstrual cycle and dysmenorrhea respectively. According to the present study findings, it was found that $71.6 \%$ \& $74.4 \%$ of women who had irregular menstrual cycle had a severe level of depression and anxiety respectively. Moreover, it was clear from the finding that, $76.5 \%$ \& $81.1 \%$ of women who had pain related to menstrual cycle had a severe level of depression and anxiety respectively. A statistically significant deviation was observed between women's menstrual cycle disturbances and their emotional hurt.

The selection of treatment depends primarily on the size of the tumor and whether the cancer has spread. The treatment choice may also depend on whether a woman would like to get pregnant someday. ${ }^{(34)}$ As documented by Zabora et al 2001, patients receiving multi-modal therapy, such as the treatment for gynecological cancers, are at risk for prolonged psychological distress that can move their overall QOL. ${ }^{(59)}$ Despite heightened risk of existential crisis and psychological distress, women who have undergone surgery for gynecological cancers do not receive optimal postdischarge care to help their physical recovery while maintaining their QOL. Care in the clinic setting instead focuses on disease management and preparation for chemotherapy; patients' existential concerns and psychological needs are considered secondarily if at all. ${ }^{(60) .}$

With respect to alterations in emotional state, the present results indicated that over the study period, depression and anxiety changed in a dissimilar way. The outcome of this study illustrated that $21.5 \%$ of the studied subject performed surgical interfering with their cancer; all of them suffer from different levels of emotional hurt. $21.0 \%$ \& $18.9 \%$ from who performed breast surgery (mastectomy, surgeries of the lymph nodes \& lumpectomy or breast conserving surgery) suffers from severe depression \& anxiety, respectively. Moreover, 4.9\% \& 5.5\% from who performed hysterectomy either simple or radical suffer from severe depression and anxiety, respectively. A highly statistically significant difference was observed between surgical management for breast and gynecologic cancer and levels of emotional distress. These findings are in agreement with the result of Schlatter M., \& Cameron L., 2010, their research demonstrates that the emotional systems of anxiety and depression have associations with physiological processes relating to cancer symptoms. (61) In summation, many subjects have shown that post surgical breast cancer patients are facing serious psychological. Consequently, most breast cancer patients experience difficulties in their ability to perform normal daily social activities, and a considerable fraction of these patients (20-46\%) seem to suffer from moderate to severe emotional morbidity. ${ }^{(48)}$

\section{Conclusion}

Emotional changes were recorded in patients with breast and gynecologic cancer. Based on our study findings, it can be concluded that there is a statistically significant association between sociodemographic, obstetrical and gynecological characteristics of women who were undergoing breast and gynecologic cancer and treatment and level of depression and anxiety symptoms

\section{Recommendation}

Granting to the research results, the following recommendations are derived:

1. Triggering off the counseling office of the nurse in clinics and inpatient obstetrics and gynecology as well as surgical departments to improve their ability to interpret the nature of mood of the woman suffering from breast and gynecologic cancer and treated easily.

2. Breast and gynecologic cancer are linked with high degrees of anxiety and depression. Furthermore, follow-up psychological examinations beside gynecologist and surgical one should be taken out by skilled experts to evaluate patient deteriorated emotional states such as depression, and anxiousness. The routine psychological screening test carried out during follow up.

3. Maternity and surgical nurses play an important part in the growth and management of malignant neoplastic disease. These calls for in-service training program for nurses in outpatient and inpatient departments of surgery, obstetrics and gynecology to raise the level of awareness to deal with women with breast and gynecologic cancer at clinics to reduce anxiety and depression associated with cancer.

\section{References}

[1] World Health Organization. World Cancer Day 2015, organized by the Union for International Cancer Control, is an opportunity to highlight the wide range of actions. 2015.

[2] American Cancer Society. Cancer Facts and Figures 2015. Atlanta, Ga: American Cancer Society; 2015. www.cancer.org.

[3] U.S. Department of Health and Human Services Centers for Disease Control and Prevention CDC Publication \#99-9125, August 2012. www.cdc.gov/ cancer/ knowledge 1-800-CDC-INFO. 


\section{International Journal of Science and Research (IJSR) \\ ISSN (Online): 2319-7064}

Index Copernicus Value (2013): 6.14 | Impact Factor (2014): 5.611

[4] Dey S. Urban-Rural Differences of Female Cancers in Gharbiah, Egypt. A thesis submitted to School of Public Health, Michigan University, 2009.

[5] Breast Cancer Deadline 2020. Org / BC Facts Figures. Breast cancer. org Discussion Board forum, 2015. DCIS (Ductal Carcinoma In Situ)

[6] Ductal Breast cancer. Fort Washington, Pa.: National Comprehensive Cancer Network. http://www.nccn.org/professionals/physician_gls/f_gui delines.asp. Accessed Feb. 17, 2014.

[7] Niederhuber JE, et al., eds. Abeloff's Clinical Oncology. 5th ed. Philadelphia, Pa.: Churchill Livingstone Elsevier; 2014. http://www.clinicalkey. com. Accessed Feb. 17, 2014.

[8] Surveillance, Epidemiology, and End Results Program (SEER): A program of the National Cancer Institute. 2014. www.seer.cancer.gov/

[9] Zawilla N. Breast cancer in Egypt: A fact sheet. The Health. 2011; 2 (1): 8-10.

[10] Pinar G., Pinar T., Akalin A., et al. Problematic Areas Related to Sexual Life of Individuals with Gynecological Cancer: A qualitative Study in Turkey. International Journal of Hematology and Oncology. 2015; 25 (3):195-204. DOI: 10.4999/ uhod.151090.

[11] Wenzel L., Donnelly J., Fowler J., et al. Resilience, reflection, and residual stress in ovarian cancer survivorship: a gynecologic oncology group study. Psycho oncology. 2002; 11: 142-153. Www. interscience.wiley.com. DOI: 10.1002/pon. 567.

[12] International Agency for Research on Cancer. Estimated cancer incidence, mortality and prevalence worldwide. 2012.

[13] Foundation for women's cancer, Gynecologic cancer awareness, research, education: Facts about Gynecologic cancers. Atlanta, Ga: American Cancer Society; 2014. www.cancer.org.

[14] U.S. Department of Health and Human Services Centers for Disease Control and Prevention. Get the Facts About Gynecologic Cancer. 2012; CDC Publication \#22-0098, www.cdc.gov/cancer/ knowledge. 1-800-CDC-INFO

[15] Giede C., Saskatoon S., Le T., et al. The Role of Surgery in Endometrial Cancer. J Obstet Gynaecol Can. 2013; 35 (4): S1-S8.

[16] American Cancer Society. Cancer Facts and Figures 2015. Atlanta, Ga: American Cancer Society; 2014. www.cancer.org.

[17] Farshbaf-Khalili A., Salehi-Pourmehr H., Shahnazi M., Yaghoubi S. and Gahremani-Nasab P.: Cervical cancer screening in women referred to healthcare centres in Tabriz, Iran. Niger Med J. 2015; 56:28-34.

[18] U.S. Department of Health and Human Services. U.S. Cancer Statistics Working Group. United States Cancer Statistics: 1999-2011. Incidence and Mortality Webbased Report. Atlanta (GA): Centers for Disease Control and Prevention, and National Cancer Institute. 2014.

[19] U.S. Preventive Services Task Force (2013): Screening for Cervical Cancer: U.S. Preventive Services Task Force Recommendation Statement. AHRQ PublicationNo.11-05156-EF-2, March 2012. Available at: http://www.uspreventiveservices taskforce.org/ uspstf11/cervcancer/ cervcancerrs. htm. Accessed November 12, 2013.

[20] Hacker N., Eifel P., Velden J. Figo Cancer Report 2012: Cancer of the vulva. International Journal of Gynecology \& Obstetrics. 2012; 119S2: S90-S96

[21] Lee L., Jhingran A., Kidd E., et al. ACR Appropriateness Criteria : management of vaginal cancer. American College of Radiology. 2013;1-11

[22] Thakur R., Nijamudin, Zheng Xue hua, et al. Clinical analysis of vulvar carcinoma. Gynecology .2013:1-5. DOI: 10.7243/2052-6210-1-5.

[23] Matsushita T., Murata H., Matsushima E., et al. Emotional state and coping style among gynecologic patients undergoing surgery. Psychiatry and Clinical Neurosciences. 2007; 61, 84-93. doi:10.1111/j.14401819.2007.01615.x

[24] Www.Beinghappybydesign.com. (2015). Depression Definition. Definition, mental health problem, suffering from depression. May 16. 2015.

[25] Hassan H. Infertility profile, psychological ramifications and reproductive tract infection among infertile women, in northern Upper Egypt. Journal of Nursing Education and Practice. 2016; 6 (4): 92-108. http://dx.doi.org/10.5430/jnep.v6n4p92.

[26] Aydin L, Yucel S. Anxiety and comfort levels of nursing students. Journal of Nursing Education and Practice. 2014; 4(8): 179-187. http://dx.doi.org/ 10.5430/jnep.v4n8p179

[27] Torpy J. Lynm C. \& Glass R. JAMA Patient page. Cancer: the basics. JAMA. 2010; 303: 1108.

[28] Chan H., Ismail S. Side Effects of Chemotherapy among Cancer Patients in a Malaysian General Hospital: Experiences, Perceptions and Informational Needs from Clinical pharmacists. Asian Pacific Journal of Cancer Prevention.2014; 15: 5305-5309. DOI: http://dx.doi.org/10.7314/ APJCP.2014.15.13.5305.

[29] American Cancer Society (ACS). (2012). Retrieved from

http://www.cancer.org/research/cancerfactsstatistics/all cancerfactsfigures/index.

[30] National Cancer Registry (2002): The National Cancer Registry News letter, Ministry of Health and Population, Egypt.

[31] Human Papilloma virus and Related Cancers, Fact Sheet 2015

[32] Centers for Disease Control and Prevention 1600 Clifton Rd. Atlanta, May 29, 2013.

[33] Ibrahim A., Khaled H., Mikhail N., et al. Cancer Incidence in Egypt: Results of the National PopulationBased Cancer Registry Program. Journal of Cancer Epidemiology. 2014. PMid: 25328522. http://dx.doi.org/10.1155/2014/437971

[34] National Cancer Institute Dictionary. (2010). Gynecologic cancer. Retrieved from http://www.cancer.gov/dictionary/?CdrID=45982.

[35] Jhingran A., Russell A. and Seiden M. Cancers of the cervix, vulva, and vagina. In: Niederhuber JE, Armitage JO, Doroshow JH, et al., eds. Abeloff's Clinical Oncology. 5th ed. Philadelphia, Pa: Elsevier Churchill Livingstone; 2013: chap 87.

[36] Vaginal cancer. www.uptodate.com (accessed September 2012). 


\section{International Journal of Science and Research (IJSR) \\ ISSN (Online): 2319-7064 \\ Index Copernicus Value (2013): 6.14 | Impact Factor (2014): 5.611}

[37] Fahmy M \& Ghally M. (www.acofps.com/up// uploads/.../acofps-334e7672fe.) مقياس تايلور للقلق الصريح.

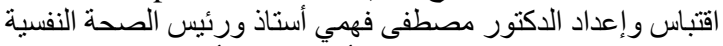

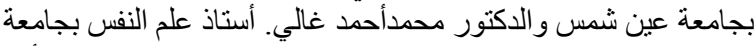
Taylor et al. Clin J Pain. 2005; 21: 91-100

[38] Sayed Y. Depression between definition and the symptoms and diagnosis. 2008. http://www. maktoobblog.com/sayed_yusuf00? Post $=22924$.

[39] Breakaway. The global burden of cancer-challenges and opportunities. The Economist. 2009.

[40] Dey S., Hablas A., Seifeldin I., et al. Urban-rural differences of gynaecological malignancies in Egypt (1999-2002). BJOG. 2010;117 (3):348-355. DOI: 10.1111/j.1471-0528.2009.02447.x

[41] Zeeneldin A., Ramadan M., Gaber A., and Taha F. Clinico-pathological features of breast carcinoma in elderly Egyptian patients: a comparison with the nonelderly using population-based data. Journal of the Egyptian National Cancer Institute. 2013; 25 (1): 5-11.

[42] Dey S., Soliman A., Hablas A., et al. Urban-rural differences in breast cancer incidence in Egypt (19992006). Breast. 2010; 19(5): 417- 423.

[43] EL Saghir N. Responding t o the Challenges of Breast Cancer in Egypt and Other Arab Countries. Journal of the Egyptian Nat. Cancer Inst. 2008; 20 (4): 309-312.

[44] World Health Organization - Cancer Country Profiles, Egypt (2014).

[45] Mohamed H., Abd Elkader R. Awareness of working women in Mansoura University about ovarian cancer: An intervention follow-up study. Journal of Nursing Education and Practice. 2016; 6 (2):10-18. http://dx.doi.org/10.5430/jnep.v6n2p10.

[46] WHO/ICO Information Centre on HPV and Cervical Cancer (HPV Information Centre) (2010): Human Papillomavirus and Related Cancers in Egypt. Summary Report. 2010. Available at www.who.int/hpvcentre

[47] Scott L.; Halford W., Ward G. The Effects of a CoupleCoping Intervention on Adjustment to Early Stage Breast or Gynecological Cancer. Journal of Consulting and Clinical Psychology. 2004; 72(6): 11221135. http://dx.doi.org/10.1037/0022-006X.72.6.1122

[48] Health line Editorial Team: Published on March 5, 2014. Medically reviewed by George Krucik, MD, MBA

[49] Gordon N. \& Siminoff L. Measuring quality of life of long-term breast cancer survivors: The long term quality of life-breast cancer (LTQOL-BC) Scale. Journal of Psychosocial Oncology. 2010; 28:589-609.

[50] Shaheen G., Arshad M., Shamim T., et al. Effects of breast cancer on physiological and psychological Health of patients. International Journal of Applied Biology and Pharmaceutical Technology.2011; 2(1): 236-243

[51] Bloom, J. Improving the health and well-being of cancer survivors: Past as prologue . Psycho-Oncology. 2008; 17: 525-532.

[52] Baker-Glenn E., Park B., Granger L., et al. Desire for psychological support in cancer. Psycho-Oncology. 2011; 20 : 525-531. DOI: 10.1002/pon.1759

[53] American Cancer Society. (2013). Cancer Facts and Figures, 2013. Atlanta, GA :American Cancer Society.
[54] Ismail Z., So W. \& Li P. Preoperative uncertainty and anxiety among Chinese patients with gynecologic cancer. Oncology Nursing Forum. 2010; 37(1): 67-74.

[56] Ell K., Xie B., Wells A., et al., Economic Stress among Low-Income Women with Cancer. Cancer. 2008; 112 (3): 616-625. DOI 10.1002/cncr.23203

[57] Upkong D, Orji MentalhealthofinfertilewomeninNigeria.2006 Winter; 17(4):259-65.

[58] Ramezanzadeh F, Aghssa M, Abedinia N, et al. A Survey of Relationship between Anxiety, Depression and Duration of Infertility. BMC women's health. 2004; $4: 9 . \quad$ PMid: 15530170 http://dx.doi.org/10.1186/1472-6874-4-9

[59] Noorbala A, Mohammad A, Bagheri S. Prevalence of psychiatric disorder in Tehran (Iran) Hakim J. 1999; 2: 214-223.

[60] Zabora J., Brintzenhofeszoc K., Curbow B. et al. The prevalence of psychological distress by cancer site. Psycho-Oncology. 2001; 10:19-28.

[61] Jones G., Ledger W., Bonnett T. et al. The impact of treatment for gynecological cancer on health-related quality of life (HRQOL): a systematic review. Am J Obstet Gynecol. 2006; 194:26-42.

[62] Schlatter M., \& Cameron L. Emotional Suppression Tendencies as Predictors of Symptoms, Mood, and Coping Appraisals during AC Chemotherapy for Breast Cancer Treatment. ann. behav. med. 2010; 40:15-29. DOI 10.1007/s12160-010-9204-6.

\section{Author Profile}

Hanan Elzeblawy Hassan is the Corresponding Author for the research, Lecturer of Maternal \& Newborn Health Nursing, Faculty of Nursing, Beni-Suef University, Egypt. An International Certified Associate Trainer in international board of certified trainers (IBCT) Certified Trainer at Center of human resources development ; Beni-Suef University, Produced and converted of the curriculum of Maternal and newborn health nursing to Electronic Learning Curriculum, Coordinator of the Maternity \& Newborn Health Nursing Department, Faculty of Nursing, Beni-Suef University, 2012-2014. Head of Midwifery Department, College of Health sciences For Girls, Albaha University, Kingdom Saudi Arabia, 2007-2009. Clinical instructor in Faculty of nursing, El Mansoura University, 1998-2009.

Magda Mohamed Bayoumi is currently working as Lecturer at Medical-Surgical Nursing Department Nursing Faculty- BSUEGYPT. she has been Assistant Professor, head of nursing department Al-farabi Colleges Riyadh, Dean College of Medical Applied Sciences , King Khalid University in the Medical \& Surgical Departments for 4 years and a lecturer in the Faculty of Nursing, King Saud University for 4 years.

Azza Mohamed Elsayed is lecturer of Obstetrics and Gynecology Nursing, Faculty of Nursing, Sohag University, Egypt. Phd degree in nursing science from faculty of nursing, benha university in 2012. Master degree in maternity \& neonatal nursing from Ain shams university in 2005. Diploma of Hospital Administration from Ain shams university in 2001. Baccalaureate degree faculty of nursing , Ain shams university in 1996. 